\title{
Capacidade estatal, burocracia e tributação nos municípios brasileiros
}

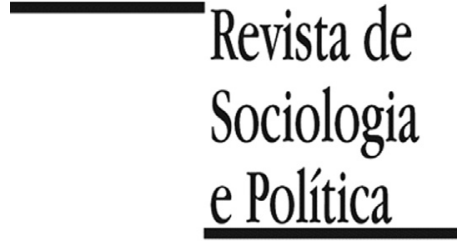

DOI 10.1590/1678-987317256401

\author{
André Marenco, Maria Tereza Blanco Strohschoen e \\ William Joner
}

Resumo

Diagnósticos sobre relações intergovernamentais e implementação de políticas públicas após a Constituição de 1988 enfatizaram os elementos de descentralização, centralização ou coordenação federativa. Sem desprezar mecanismos institucionais que estruturam relações verticais entre governos federal, estadual e municipais, este trabalho pretende analisar diferenças entre os 5,5 mil municípios brasileiros no que diz respeito a indicadores de sua capacidade estatal. Busca-se examinar em que medida municípios com burocracias profissionalizadas tiveram melhores condições para aproveitar a transferência de responsabilidades e autoridade política e administrativa para governos municipais, ampliando seu potencial para tributar e implementar políticas públicas. Adotou-se a definição restrita de capacidade estatal, utilizando-se a "escala weberiana" proposta por Evans e Rauch como medida. Para operacionalizá-la, foi considerada a proporção de "estatutários com formação superior" entre servidores públicos nas 5,5 mil administrações municipais brasileiras. Como variável dependente, foi utilizada a arrecadação de Imposto sobre a Propriedade Predial e Territorial Urbana como proporção da receita própria municipal. Os resultados mostraram que administrações municipais com serviço público mais profissionalizado incrementam suas razões de chance para arrecadação do imposto patrimonial.

Palavras-chave: governos municipais; capacidade estatal; burocracias; tributação; políticas públicas.

Recebido em 14 de Outubro de 2016. Aceito em 16 de Janeiro de 2017.

\section{Introdução ${ }^{1}$}

\author{
${ }^{1}$ Agradecemos aos \\ comentários e sugestões dos \\ pareceristas anônimos da \\ Revista de Sociologia e \\ Política.
}

$\mathrm{O}$ propósito deste texto consiste em analisar diferenças existentes entre os 5.570 municípios brasileiros no que diz respeito a indicadores de sua "capacidade estatal". A primeira seção promove uma revisão da literatura sobre relações intergovernamentais e o debate internacional acerca de "capacidades estatais". Adotando tratamento analítico restrito à noção de "capacidades estatais", buscou-se distinguir recursos e mecanismos geradores de capacidades estatais - como graus de profissionalização de burocracias governamentais - e efeitos produzidos por sua disponibilidade, sob a forma de implementação de policies. Considerando os efeitos redistributivos e custos políticos de um imposto municipal como o IPTU (Imposto Predial e Territorial Urbano), a segunda seção do texto fez um inventário de diferentes explicações para a variação em sua arrecadação: tamanho do município, transferências intergovernamentais, preferências ideológicas e custos políticos. A terceira seção apresenta os procedimentos analíticos adotados e os resultados alcançados. Utilizando bases de dados sobre municípios brasileiros (Munic/IBGE, Finbra, Tribunal Superior Eleitoral e Atlas/UFRGS), e empregando testes estatísticos, identificou-se variações da participação do IPTU na receita própria municipal, cotejando-as com distintos fatores explicativos: (1) tamanho do município; (2) partidos e competição eleitoral; (3) profissionalização da burocracia municipal. Finalmente, a conclusão analisa os achados encontrados, retomando o argumento que percorre todo o texto sobre as conexões entre burocracias profissionais e redução de custos políticos e administrativos para a taxação redistributiva. 


\section{Capacidades estatais e relações intergovernamentais}

2 Tal modalidade de transferência foi definida pelo artigo 25 da Lei de Responsabilidade Fiscal de 2000 como "a entrega de recursos correntes ou de capital a outro ente da Federação, a título de cooperação, auxílio ou assistência financeira, que não decorra de determinação constitucional, legal ou os destinados ao Sistema Único de Saúde".

3 Ver Constituição Federal, especialmente Art. 30, incisos III (tributos municipais), V (serviços públicos) e VIII (ordenamento territorial, uso e ocupação do solo urbano).
A Constituição de 1988 promoveu descentralização política com transferência de receitas, responsabilidades e autoridade administrativa, fiscal e política para governos subnacionais, associada à maior disponibilidade de recursos financeiros gerada pelo incremento em receitas próprias e de transferências intergovernamentais. Desde 2003, as transferências voluntárias ${ }^{2}$ para municípios ultrapassaram a cota destinada aos estados, revelando oportunidades crescentes para a obtenção de receita por meio de convênios e programas conjuntos com a União (Falleti 2005), além do fato de terem-se tornado recursos atraentes e cobiçados enquanto fonte de implementação adicional para outras políticas públicas no nível local (Soares 2012). O novo status ampliou prerrogativas políticas e administrativas locais (Falleti 2010); promoveu maior taxação própria e, principalmente, aumento nas transferências constitucionais da União e dos Estados para os municípios, possibilitando maior receita fiscal para estes entes. Ao mesmo tempo, a municipalização de serviços conferiu-lhes maior responsabilidade na promoção do desenvolvimento econômico local e de bens públicos ${ }^{3}$.

Diferentes diagnósticos sobre relações intergovernamentais e implementação de políticas públicas neste período enfatizaram alternativamente o predomínio de elementos de descentralização (Stepan 1999; Samuels \& Abrucio 2000; Samuels 2004; Falleti 2005; 2010) centralização (Arretche 2009; 2013; Almeida 2005; Melo 2005) ou coordenação federativa (Abrucio \& Sano 2011; Abrucio, Franzese \& Sano 2013; Franzese 2010; Dieguez 2011; Fernandes \& Araújo 2015; Klink 2010).

Sem desprezar mecanismos institucionais que estruturam relações verticais entre governos federal, estadual e municipais, este trabalho pretende analisar diferenças horizontais entre os municípios brasileiros no que diz respeito a indicadores de sua capacidade estatal (Evans 1995; Kohli 2010; Cingolani 2013; Cingolani, Thomsson \& Crombrugghe 2013; Gomide, Silva \& Pires 2014; Evans, Huber \& Stephans 2014; Centeno, Kohli \& Yashar 2017; Gomide $\&$ Boschi 2016). Busca-se identificar fatores locais que contribuíram para uma ampliação, por parte dos governos municipais, da capacidade de implementar políticas públicas e de arrecadar impostos próprios. Dessa forma, o presente trabalho também busca analisar as questões suscitadas sob a ótica do plano municipal, âmbito no qual as políticas públicas são implementadas e que, aos poucos, vem ganhando relevância na literatura da Ciência Política (Pereira, Nakabashi \& Sachida 2011).

O modelo de capacidades estatais tem sido empregado na análise de problemas diversos como controle da violência (Huntington 1968), crescimento econômico (Evans 1995; Evans \& Rauch 1999; Fiani 2014; Gomide, Silva \& Pires 2014), prosperidade (Acemoglu \& Robinson 2012), condições favoráveis para democracias (Tilly 2007) ou qualidade de democracias (Rothstein 2011). Por outro lado, a amplitude analítica conferida ao conceito de "capacidades estatais", terminou por associá-lo a múltiplas dimensões como "coercitiva", "legal", "administrativa", "fiscal", "política", "transformativa" e "territorial". Não parece difícil identificar uma circularidade entre os meios necessários para a provisão de capacidade estatal (coerção, leis e burocracia administrativa), com efeitos produzidos por sua disponibilidade (Cingolani 2013; Cingolani, Thomsson \& Crombrugghe 2013) como ampliação da arrecadação fiscal, potencial para regulamentação do investimento, oferta de serviços públicos e legitimidade política.

Para evitar esta circularidade, o sentido restrito de capacidade estatal a ser empregado aqui equivale à intervenção de agentes estatais utilizando meios 
como coerção, decisões, regulamentos, procedimentos, leis, informação, capacidade de alterar a distribuição de recursos, prerrogativas, status, renda ou propriedade previamente fixados (efeitos), conforme depreende-se da seminal definição de Tilly:

"State capacities means the extent to which interventions of state agents in existing non-state resources, activities and interpersonal connections alter existing distributions of those resources, activities and interpersonal connections as well as relations among those distributions" (Tilly 2007, p.16).

Pretende-se, na análise a seguir, separar mecanismos e efeitos associados a capacidades estatais nos governos municipais. No federalismo brasileiro, municípios não possuem prerrogativas para o exercício da coerção ou promoção de segurança pública, não permitindo a busca de diferenças salientes neste quesito que pudesse explicar variações em termos de sua capacidade para alterar ou interferir sobre relações entre agentes públicos e privados no plano local. Municípios estão também submetidos a arranjo jurídico emanado da Constituição Federal, com margens restritas de inovação legal sem que estas possam ser consideradas inconstitucionais. Governos municipais possuem prerrogativas de legislar sobre tributos municipais, como IPTU ou Imposto sobre Serviços de Qualquer Natureza (ISS), mas as variações na legislação tributária e fixação de alíquotas devem ser interpretadas mais como efeito da relação de forças entre governos e agentes privados locais.

Nesta perspectiva, a opção metodológica adotada foi empregar um sentido restrito a "capacidades estatais", delimitando-as à profissionalização da burocracia governamental municipal e sua participação relativa no conjunto do funcionalismo municipal, contribuindo para ampliar o poder de agência governamental (Grín 2012). Assim, o desempenho do aparato burocrático fortalece as habilidades do Estado e as condições para implementar políticas (Olsen 2005; Evans 1995; Evans \& Rueschmeyer 2002; Geddes 1986; Selznick 1984). Evans e Rauch (1999) consideraram recrutamento meritocrático e carreiras profissionais de longo prazo como indicadores para construir uma "escala weberiana" visando mensurar a profissionalização do serviço público em uma amostra de 35 países em desenvolvimento, entre os anos 1970 e 1990. Seus resultados mostraram forte correlação $(\mathrm{r}=0,67$, significativa a $1 \%)$ entre índices de profissionalização burocrática e crescimento econômico, medido pela variação do PIB per capita no período. Em contraste, foi descartada relação inversa (desenvolvimento $>$ profissionalização) rejeitando a suposição de que a profissionalização na administração pública fosse produto de prosperidade econômica ${ }^{4}$. Posteriormente, Kohli (2010), adaptou a "escala weberiana" como uma proxy de "capacidade estatal", replicando novamente a relação entre qualidade da burocracia pública e indicadores de desempenho econômico de países em desenvolvimento.

A relação lógica entre burocracia profissional e seu impacto sobre a distribuição de atividades ou recursos não reside na crença weberiana da racionalidade ou eficiência superior dos funcionários de carreira, mas na inferência de que recrutamento meritocrático e carreiras profissionais estáveis promovem a autonomia destes agentes em relação a ciclos políticos e eleitorais, ao mesmo tempo em que a informação técnica disponível incrementa sua influência na agenda de políticas públicas, em especial quanto a policies redistributivas, que envolvem relações de soma-zero entre ganhadores e, sobretudo, perdedores dispostos ao veto nestas arenas (Olsen 2005; Cook 2010; Evans, Huber \& Stephens 2014).

Pode-se encontrar reduzido número de trabalhos que dedicam-se a investigar dimensão e perfil de burocracias governamentais locais no Brasil e sua relação com a implementação de policies municipais. Analisando a dimensão 
do funcionalismo público nos municípios brasileiros no intervalo dos mandatos executivos municipais de 2005 e 2008, Barone (2010) registrou uma variação de $18 \%$ no contingente de servidores públicos, com um incremento de $38,5 \%$ no volume de gasto com pessoal, a despeito de redução $(-2,2 \%)$ na participação relativa dos salários no orçamento das administrações locais, Para explicar este fenômeno, Barone identificou três padrões: (1) prefeitos em primeiro mandato contratam mais servidores, ampliando o gasto com pessoal do que o promovido por incumbents reeleitos; (2) quanto maior a competição eleitoral, maior a expansão do emprego público municipal pós-eleitoral; (3) ocorrência de padrões partidários em relação à expansão do emprego público municipal. Em paralelo, os resultados de Vieira (2009) indicaram que o escopo do setor público municipal é positivamente correlacionado com a expectativa de transferências intergovernamentais e é associado negativamente com a projeção da produção privada local.

Contribuição significativa pode ser encontrada no trabalho de Batista (2015), que analisa o impacto de medidas de qualidade da burocracia municipal e a implementação de recursos provenientes de transferências federais. Utilizando dados da fiscalização exercida pela Controladoria Geral da União por meio de sorteios de municípios, a autora encontrou relação significativa entre número de funcionários por habitante e proporção de servidores com escolaridade superior, de um lado, e menor frequência de irregularidades no uso de recursos federais, de outro.

Assim, escala e perfil profissionalizado do serviço público local ampliam o potencial para eficiência na alocação de recursos originários de transferências federais e, conforme Dos Santos (2009), é pressuposto para que as organizações públicas possam ingressar em patamar diferenciado, tornando-se menos sensíveis a interferências fisiológicas ou clientelistas que em regra impedem que as organizações possam ser geridas de forma racional tendo como horizonte o interesse público e a continuidade de suas políticas públicas. Contudo, o problema a ser respondido neste trabalho possui uma inflexão distinta, buscando responder se a expertise técnica e autonomia política de burocracias profissionalizadas ampliam a probabilidade para a adoção de legislação e policies orientadas por parâmetros redistributivos, envolvendo identificação de perdedores - patrimônio imobiliário urbano - com custos políticos e eleitorais decorrentes de provável rejeição ao incremento em carga tributária específica.

Perspectiva alternativa para explicar variações entre governos municipais diz respeito ao impacto de ciclos eleitorais e partidários sobre (1) escolhas sobre gasto, taxação e políticas públicas e (2) padrões de relações intergovernamentais. O problema aqui reside em que não apenas governos municipais constituem um tema pouco investigado na produção sobre instituições políticas da federação brasileira, mas, principalmente pelo fato que os estudos sobre competição eleitoral local, em sua maioria, não conectam politics e policies, ou seja, ciclos partidários com padrões de gasto público ou política fiscal municipal.

Estudos sobre política municipal têm se debruçado sobre o impacto de mudanças demográficas sobre a competição eleitoral local (Avelar \& Walter 2008), graus de competição partidária em decorrência do tamanho do município (Campello de Souza 2006), recursos empregados na disputa por cadeiras nos legislativos municipais (Kerbauy 2005; Felisbino, Bernabel \& Kerbauy 2012), variáveis políticas na eleição de prefeitos municipais (Codato, Cervi \& Perissinotto 2013), incentivos para corrupção nos municípios (Batista 2013), subordinação das eleições locais às estaduais e nacionais (Almeida \& Carneiro 2003; Piquet \& Almeida 2008) e influência de alinhamentos eleitorais intergovernamentais na disputa por executivos municipais (Marenco 2013). 
Estes estudos mostram que embora haja uma melhora na compreensão da politics local, permanecem ainda pouco exploradas as conexões entre padrões de competição eleitoral e partidária e preferências governamentais locais por gasto público e política fiscal. Exceção pode ser encontrada em estudo de Sátyro (2013), revelando que a política no nível subnacional importa para a redistribuição de renda, com evidências paradoxais de que partidos de centro e de direita tiveram um efeito redistributivo maior do que os governos petistas no período analisado.

\section{Por que se taxa pouco IPTU no Brasil?}

O debate brasileiro sobre política fiscal e relações intergovernamentais concentra-se sobre a dimensão comparativa da carga tributária em relação ao PIB, bem como a participação dos diferentes entes federados na receita disponível total (Paes \& Bugarin 2006). Em 2013, a carga tributária bruta no Brasil representava 33,7\% do Produto Interno Bruto, um pouco abaixo da média (35\%) dos países da OCDE (RFB 2014, p.10). Em termos da competência em sua geração, conforme dados da Receita Federal (RFB 2014, p.5), tributos federais arrecadaram $23,3 \%$ do PIB, acima da receita produzida por taxação estadual $(8,5 \%)$ e municipal $(1,9 \%)$. Por outro lado, a composição da carga tributária em relação à sua base de incidência tem sido mais negligenciada: enquanto bens e serviços $(41,2 \%)$, salários e mão de obra $(21,5 \%)$ respondem por quase dois terços da receita arrecadada, renda, lucro e ganhos $(19,9 \%)$ e bens patrimoniais $(3,6 \%)$ revelam uma subtaxação de ativos ligados à propriedade, o que se torna mais saliente quando comparado à tributação patrimonial em países da OCDE (RFB 2014, p.12). Os 1,3\% de tributos patrimoniais arrecadados no Brasil distam dos valores registrados em economias de mercado como EUA (2,8\%), Canadá (3,2\%), França ( $3,8 \%)$ ou Reino Unido $(4,1 \%)$. O predomínio de tributos indiretos produz efeito regressivo sobre a distribuição de renda, uma vez que incrementa sua concentração pós-taxação.

Segundo Guedes (2001), a política fiscal é o ponto culminante do processo de planejamento e condição necessária para ampliar sua capacidade de arrecadação própria e reduzir a dependência das transferências federais e estaduais. Os municípios possuem competência para tributar a propriedade imobiliária urbana e sua transmissão, podendo definir taxas, isenções, cadastro, arrecadação e cobrança do Imposto Predial e Territorial Urbano (IPTU) e do Imposto sobre

${ }^{5}$ Outros tributos patrimoniais são de competência da União (Imposto Territorial Rural) ou dos estados (Imposto sobre Propriedade de Veículos Automotores e Imposto sobre Transmissão, Causa Mortis e Doação de Quaisquer Bens ou Direitos).
Transmissão de Bens Intervivos (ITBI) 5 . Possuem, principalmente, a arrecadação do Imposto Sobre Serviços (ISS), que em 2014 representou R \$ 55,4 bilhões ou $3 \%$ da receita tributária nacional, equivalente a $1 \%$ do PIB brasileiro. Ao seu lado, o IPTU somou R $\$ 27,9$ bilhões, equivalente a 1,5\% da receita fiscal nacional ou, ainda, 0,51\% do PIB brasileiro (RFB 2014, p.15). Em 86\% dos municípios, a arrecadação do IPTU é inferior à receita gerada pelo ISS (RFB 2014). A importância dos "serviços" na arrecadação tributária municipal, respondendo por aproximadamente duas vezes a receita proveniente da propriedade territorial urbana, produz consequências sobre a forma de incentivo à competição fiscal entre municípios e impacto regressivo da taxação (Afonso \& Castro 2014).

Estudo comparativo empreendido por De Cesare (2010) com base em 66 jurisdições subnacionais em 13 países da América Latina revelou igualmente reduzida participação do imposto sobre propriedade imobiliária na geração da receita de instituições públicas da região, situando-se em valores médios equivalentes a $1,6 \%$ do total arrecadado. Chile $(3,3)$, Panamá $(2,2)$ e Paraguai $(1,9)$ situam-se nos patamares superiores em relação à importância desta receita, enquanto Costa Rica $(0,6)$, Peru $(0,9)$ e República Dominicana $(0,9)$ representam casos de menor participação relativa de tributos sobre propriedade imo- 
${ }^{6}$ A taxação progressiva do IPTU pode ocorrer de duas formas: no tempo e no espaço. Interessa-nos a taxação progressiva no espaço, ou seja, em função do valor venal, permitida com a aprovação da Emenda Constitucional 29/2000. Segundo De Cesare (2007), quando existe uma graduação do ônus tributário, por meio da adoção de alíquotas progressivas, $o$ objetivo é gerar um impacto sobre o poder econômico do contribuinte, visando reduzir as disparidades sociais entre os indivíduos. biliária na receita estatal. Considerando a jurisdição dos órgãos responsáveis por lançamento, arrecadação e fiscalização deste tributo, De Cesare identificou o Chile como o caso de maior centralização na sua administração, enquanto Venezuela, Brasil (no caso do IPTU) e Argentina (Tasas Municipales), aqueles de competências mais descentralizadas.

Como pode ser explicada esta subtaxação do IPTU? Para Sepúlveda e Vazquez (2009) a participação do IPTU na receita municipal é uma função do tamanho do município, uma vez que localidades pequenas implicam menor base tributária. Smolka e Furtado (1994) e Mattos, Rocha e Arvate (2011) testam relação entre maior volume de transferências do governo central e uma redução nos incentivos para eficiência na arrecadação de impostos locais. Garson (2007) analisa investimentos administrativos na manutenção de cadastros, monitoramento e revisão de valores venais, uma vez que a arrecadação não se baseia em declaração, mas na comprovação efetiva da propriedade e suas dimensões. Bahl (2009) e Afonso, Araújo e Nóbrega (2012; 2013) enfatizam os custos políticos e administrativos para a aprovação de impostos patrimoniais, decorrentes de pontos de veto para decisões legislativas e dificuldades operacionais para gravação e recolhimento.

Taxação ${ }^{6}$ sobre propriedade imobiliária identifica um tipo de política redistributiva (Lowi 2009; Sefter 2006; Cook 2010; Steinmo 1989) caracterizada por modificar a alocação de recursos existentes. À medida que impõe perdas a interesses delimitados e identificáveis sob a forma dos custos necessários para a geração de uma receita nova, transferida sob a forma de benefícios concentrados a outros grupos sociais ou econômicos, políticas produzidas em arenas redistributivas projetam conflitos de soma-zero mais intensos entre perdedores e ganhadores. Ao contrário de tributação indireta, cujos custos se distribuem de modo difuso entre todos os contribuintes - independentemente de sua renda pré-tributação - dificultando a percepção de ônus ou perdas. Além disso, os benefícios muitas vezes são alocados de modo concentrado (e, por isto, potencialmente com alto feedback positivo), taxação sobre a propriedade mobiliza reações de potenciais alvos da redistribuição fiscal. $\mathrm{O}$ fato de envolver, ainda, tributação sobre fixed assets (Boix 2003) explicaria ampliação de áreas de veto sobre esta policy. A adoção de uma política fiscal redistributiva, com a imposição de custos a segmentos específicos sob a forma de taxação à propriedade não implica, automaticamente, preferências orçamentárias redistributivas, ou seja, na implementação de policies que representem incremento no gasto social ou com programas de transferência de renda. Diferentes fatores podem levar a escolha de uma política fiscal redistributiva - indisponibilidade de outras receitas, rupturas, baixos custos políticos - da mesma forma que a receita gerada poderá ser objeto de barganha, disputa e alocação fragmentada. Steinmo (1989) mostra como a política fiscal norte-americana foi mais redistributiva do que a adotada no Reino Unido ou Suécia, esta marcada por tributação predominantemente indireta. Por outro lado, Esping-Andersen (1990) revela os efeitos redistributivos e universais das políticas sociais escandinavas e, em menor medida, britânicas, em contraste com um orçamento mais regressivo adotado nos governos norte-americanos.

Política fiscal redistributiva estaria relacionada à competição eleitoral? Um dos principais modelos associando políticas fiscais redistributivas e competição eleitoral pode ser encontrada no teorema do eleitor mediano (Downs 1957; Larcinese 2007). Nesta perspectiva, governos promovem escolhas por políticas considerando preferências de seus eleitores potenciais: quando a renda do votante mediano situa-se abaixo da renda média, este eleitor possui incentivos para apoiar programas redistributivos, que transferem renda por meio de tributação e serviços sociais; inversamente, eleitores com renda elevada não teriam incentivos para promover políticas redistributivas, uma vez que estas incre- 
mentam a carga fiscal e estes não estariam entre os beneficiados por políticas de transferência de renda. A associação entre partidos de esquerda e políticas redistributivas, e a oposição de legendas liberais à tributação progressiva tem sido amplamente explorada na literatura (Hibbs Jr. 1977; Alesina \& Rosenthal 1995; Wittman 1995; Schmidt 1996; Castles \& Obinger 2007). Analisando comparativamente Estados Unidos, Reino Unido e Suécia, Steinmo (1989) identificou uma associação entre maior fragmentação política e institucional, incremento relativo de taxação progressiva e menor arrecadação de tributos indiretos sobre consumo no caso norte americano; governos de maioria unipartidária como no Reino Unido tendem a promover alternância entre políticas fiscais progressivas e regressivas e governos minoritários ou de coalizão, a exemplo da Suécia, aumentam a probabilidade de políticas conciliatórias e de taxação indireta sobre consumo, o que aumenta o apoio a gastos redistributivos e reduz a evasão de investimentos.

\section{Procedimentos e resultados}

Esta seção procura analisar evidências sobre as variações na arrecadação do IPTU entre os municípios brasileiros. Para dar conta deste propósito, utiliza diferentes bases de dados sobre administrações municipais como a Pesquisa de Informações Básicas Municipais, do IBGE (Munic), as Finanças do Brasil Dados Contábeis dos Municípios, publicadas pela Secretaria do Tesouro Nacional (Finbra) e o Atlas Eleitoral do Rio Grande do Sul, da Universidade Federal do Rio Grande do Sul (Atlas). Empregando análise descritiva e testes estatísticos, pretende-se examinar a participação do IPTU na arrecadação municipal, relacionando variações na arrecadação do imposto patrimonial com (1) o tamanho dos municípios, (2) ciclos partidários e eleitorais e (3) perfil e qualidade da burocracia municipal. Os resultados são apresentados a seguir.

O primeiro passo da análise dos dados consistiu em considerar a participação relativa dos principais tributos municipais na arrecadação de impostos pelos governos municipais em um intervalo de 10 anos, entre 2002 e 2012. A escolha deste período levou em conta os seguintes fatores: (1) a literatura sobre política fiscal nos governos municipais - revisitada acima - já apresenta evidências longitudinais abundantes sobre a contribuição reduzida do imposto sobre o patrimônio territorial urbano nos impostos arrecadados, sobretudo quando cotejado com receita gerada por transferências de impostos indiretos (ICMS); (2) preocupação em capturar tendências recentes sobre o comportamento dos principais tributos municipais, subsidiando a análise prioritária a seguir sobre a subtaxação do IPTU; (3) as mudanças registradas na esfera governamental federal a partir de 2002 e a tentativa de identificar eventual influência na esfera local sob a forma de incremento em política fiscal redistributiva; (4) a consideração de pelo menos três ciclos governamentais no plano municipal; (5) indisponibilidade de dados para séries mais amplas. As informações sobre arrecadação municipal podem ser examinadas no Gráfico 1.

A participação do IPTU na arrecadação fiscal própria dos municípios brasileiros apresenta trajetória decrescente. Situando-se em 21,5\% dos valores médios arrecadados pelos governos municipais em 2002, este percentual apresenta sucessivas reduções, alcançando apenas $14,2 \%$ da carga tributária local dez anos mais tarde, representando uma queda de $33,9 \%$ na contribuição relativa deste tributo para a receita própria das administrações dos municípios. Em 2012, a participação do IPTU nivelou-se com o aporte representado pelo Imposto Sobre Transmissão Intervivos (ITBI), que apresentou comportamento mais estável ao longo deste intervalo temporal. Inversamente, o Imposto Sobre Serviços (ISS) apresenta um incremento em sua participação, de 33,3\% em 2002, para $46,1 \%$, em 2012, correspondendo a um aumento de $38,4 \%$ de seu 
Gráfico 1 - Participação na arrecadação municipal, principais impostos (2012)
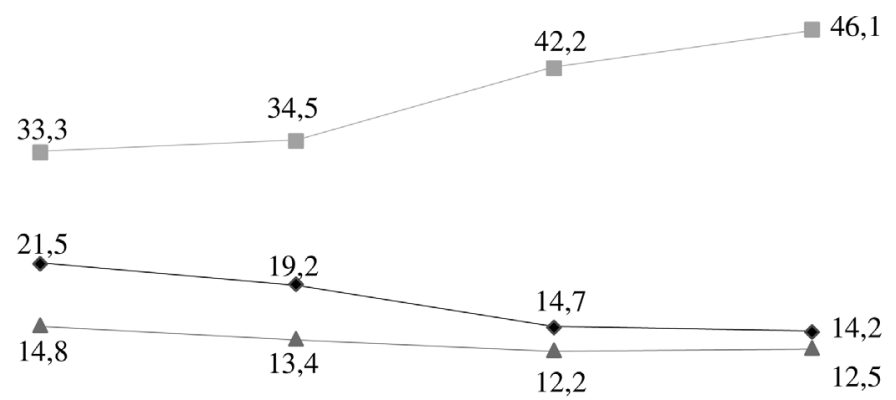

$\begin{array}{lccc}2002 & 2004 & 2008 & 2012 \\ & + \text { iptu }- \text { iss }- \text { - itbi }\end{array}$

Fontes: Tesouro Nacional, IBGE (2015) e Atlas-UFRGS (2016).

${ }^{7}$ Agradecemos a um dos pareceristas anônimos pela lembrança deste fato. peso relativo. A edição da Lei Complementar 116, em julho de 2003, ampliou a base de serviços sujeitos à tributação do ISS, contribuindo para o incremento em sua arrecadação, reduzindo, ao mesmo tempo, pressões pelo aumento no imposto patrimonial urbano ${ }^{7}$.

Uma hipótese para explicar as variações na arrecadação do IPTU está relacionada ao tamanho dos municípios. Cidades de pequeno porte e baixa população apresentariam base tributária mais reduzida, ao mesmo tempo em que custos de transação política mais elevados, decorrentes da proximidade pessoal entre autoridades e potenciais contribuintes. Para verificar esta ocorrência, os municípios foram divididos conforme sua população, em "micro" (menos de 10 mil habitantes), "pequenos" (10 a 50 mil habitantes), "médios" (50 a 100 mil) e "grandes" (acima de 100 mil habitantes). Foram considerados os valores médios e medianos relativos à participação do IPTU na arrecadação municipal própria. Os resultados são apresentados no Gráfico 2.

Gráfico 2 - IPTU em relação a impostos municipais, conforme tamanho município (2012)

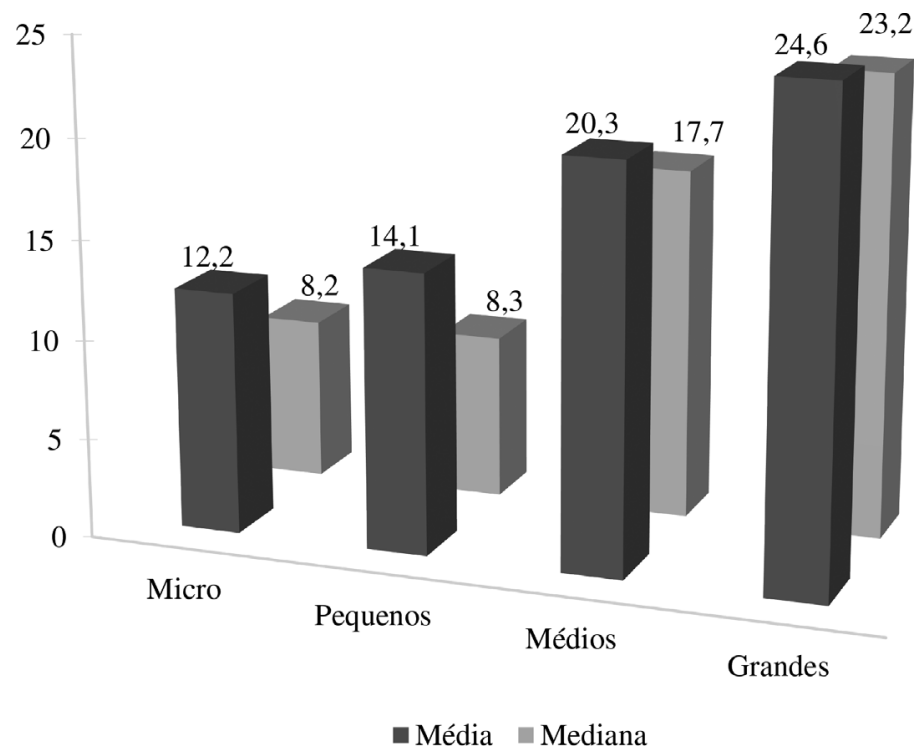

Fontes: Tesouro Nacional, IBGE (2015) e Atlas-UFRGS (2016). 
${ }^{8}$ O Fundo de Participação dos Municípios (FPM) tem origem no art. $21^{\circ}$, da Emenda Constitucional 18 , de $1^{\circ}$ de dezembro de 1965 , tendo sido regulamentado pela Lei 5.172, de outubro de 1966 e ratificado pelo art. $159^{\circ}$, da Constituição Federal de 1988 (Secretaria do Tesouro Nacional 2012).
Conforme o previsto, observa-se uma variação saliente na contribuição do imposto imobiliário urbano para a arrecadação municipal, conforme aumenta o tamanho de cada cidade. Em municípios de porte "micro" o IPTU representa apenas $12,2 \%$ dos tributos arrecadados. No extremo oposto, em cidades com mais de 100 mil habitantes, o imposto sobre o patrimônio territorial urbano atinge a escala de $24,6 \%$ da arrecadação tributária municipal. Em paralelo, deve-se salientar o comportamento dos valores médios e medianos, conforme o tamanho dos municípios. Observa-se uma discrepância maior nas "micro" e "pequenas" cidades, enquanto os valores tornam-se mais homogêneos, com o aumento da escala urbana. Deve-se considerar que a participação relativa no Fundo de Participação dos Municípios (FPM) é menor à medida em que cresce o tamanho da cidade. Desta forma, grandes municípios necessitam aumentar sua arrecadação própria para compensar menor fluxo de transferências ${ }^{8}$.

Em que medida, partidos fazem diferença na definição da política fiscal das administrações municipais brasileiras? É de se esperar que partidos de esquerda adotem programas redistributivos, preferindo um perfil fiscal mais progressivo, que tribute mais fortemente renda e propriedade. Como imposto sobre a renda não faz parte das competências constitucionais municipais, seria previsível que a taxação sobre a propriedade urbana constitua um instrumento escolhido por governos com agenda redistributiva para gerar receita a ser realocada sob a forma de gasto social. Inversamente, espera-se que partidos conservadores ou liberais sejam mais comedidos na taxação sobre propriedade. Para verificar estes postulados, o gráfico seguinte registrou os valores medianos relativos à participação do IPTU na arrecadação tributária local para o ano de 2012, considerando o partido do Prefeito Municipal eleito em 2008 para o período 2009/2012. Optou-se pela utilização de valores medianos para melhor controlar distorções eventualmente provocados por valores médios considerando diferentes tamanhos de municípios. Os dados podem ser examinados no Gráfico 3.

Os resultados apresentam dois comportamentos paradoxais: prefeituras conquistadas pelo Partido Progressista (PP) em 2008 apresentaram os maiores valores medianos de arrecadação de IPTU em 2012; no extremo oposto, cidades que elegeram prefeitos comunistas do PCdoB corresponderam ao menores valores medianos do imposto patrimonial, apresentando um comportamento invertido em relação ao padrão esperado: conservadores e menor arrecadação fiscal $v s$. comunistas ou esquerdistas e maior arrecadação fiscal.

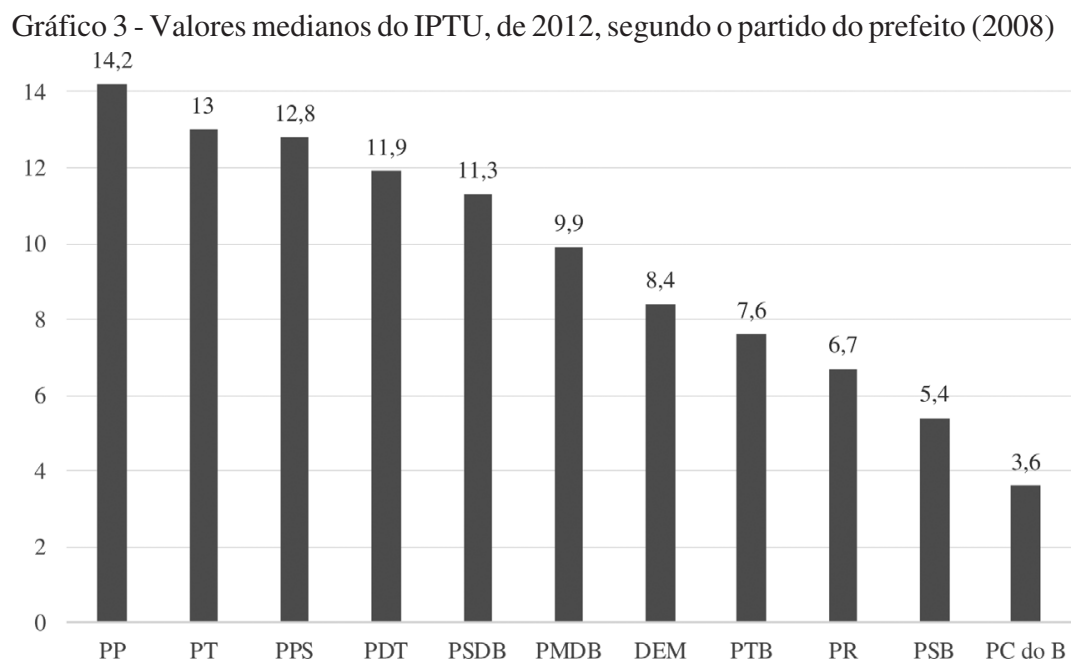

Fontes: Tesouro Nacional, IBGE (2015), TSE e Atlas-UFRGS (2016). 
Por outro lado, não se deve negligenciar que a estrutura fiscal em cada município provavelmente obedeça a um padrão path dependant, com mudanças incrementais de uma gestão a outra. Nesta perspectiva, uma hipótese sugestiva parece ser a de que municípios com uma carga fiscal redistributiva mais elevada, com maior taxação sobre patrimônio imobiliário, tenham optado por eleger prefeitos mais liberais ou conservadores, visando reduzir a pressão fiscal sobre a propriedade. Em extremo oposto, cidades nas quais o imposto patrimonial é menor, a pressão sobre a propriedade é mais baixa, os conflitos redistributivos são menos intensos, existindo maior margem de tolerância para experimentação com administrações teoricamente mais radicais.

Neste ponto, parece relevante considerar a variação no comportamento do IPTU durante a administração municipal, segundo diferentes legendas partidárias. Este procedimento permite captar as preferências partidárias implementadas em suas respectivas administrações, em termos de incremento ou redução fiscal. Para isto, foram observadas as variações medianas da arrecadação de IPTU entre 2008 e 2012 - correspondendo a um ciclo completo de governos municipais (Gráfico 4).

Agora, o comportamento partidário parece corresponder ao padrão esperado. Embora a redução na arrecadação do IPTU tenha correspondido a um padrão comum, sua escala variou conforme as inclinações políticas das principais legendas partidárias à frente de governos municipais. A distribuição desta variação parece consistente com uma escala direita-esquerda, correspondendo a preferência por menor ou maior taxação. Prefeitos do PP apresentaram maiores índices de contração na arrecadação fiscal patrimonial, seguidos por PSDB, PMDB e DEM. No extremo oposto, PDT, PSB, PT e PCdoB - com a intrusão do PR neste grupo - revelaram maior vinculação a este tributo.

Gráfico 4 - Variações medianas IPTU, segundo os principais partidos (2008-2012)

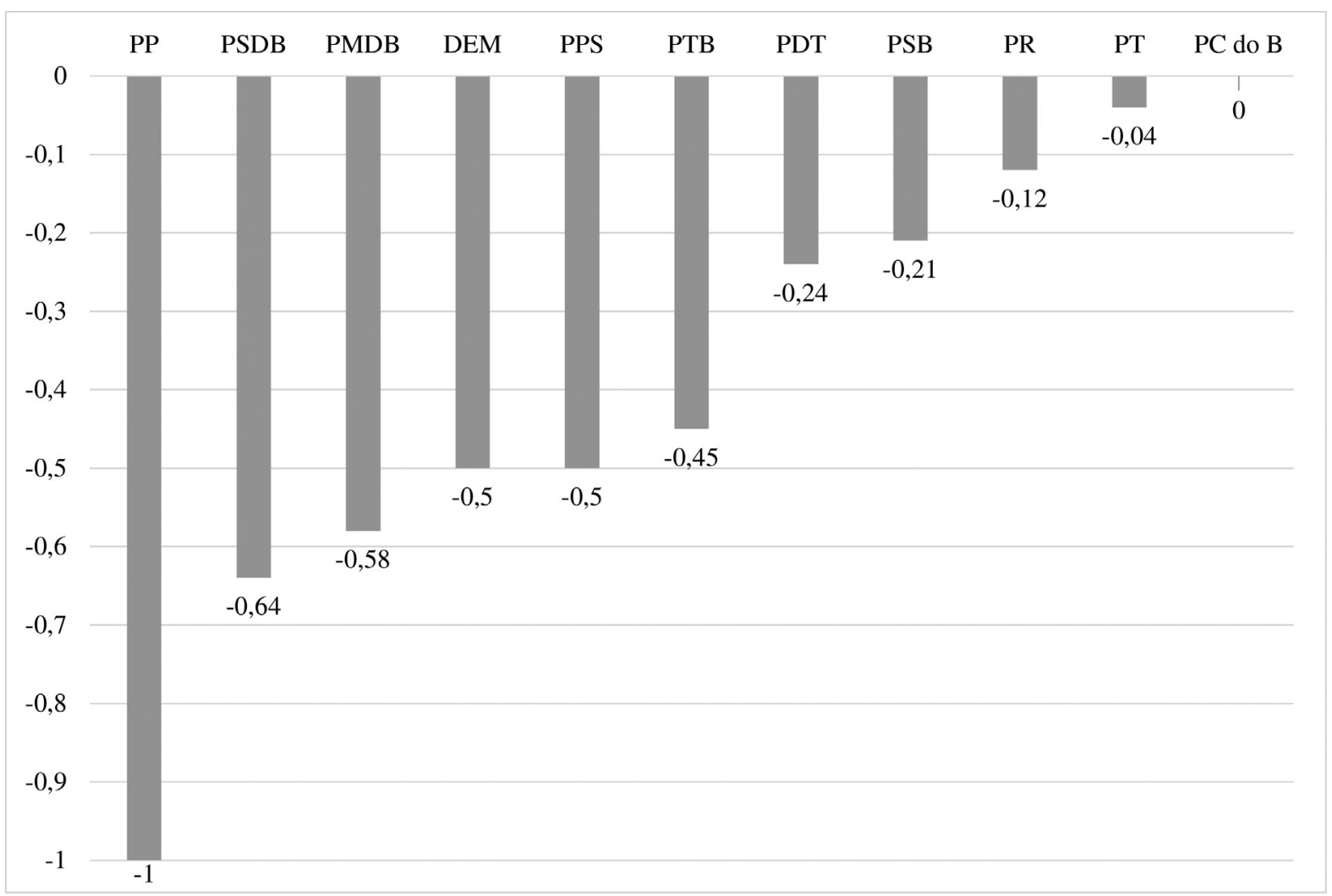

Fontes: Tesouro Nacional, IBGE (2015), TSE e Atlas-UFRGS (2016). 
Em que medida a política fiscal adotada durante o mandato no Executivo municipal afeta as chances de continuidade do mesmo partido - por meio do incumbent ou de seu sucessor - nas eleições seguintes? Faz diferença nas chances de reeleição aumentar ou diminuir o imposto predial e territorial urbano? Em municípios em que a arrecadação de IPTU registrou redução superior a quatro pontos percentuais, a manutenção da mesma legenda partidária no governo municipal representou $29,3 \%$ dos casos. No extremo oposto, nas administrações municipais em que a receita gerada pelo IPTU conheceu incremento superior a quatro pontos percentuais entre 2008 e 2012, a continuidade partidária alcançou a 26,9\% das situações. Moderada variação no IPTU (entre $-4 \%$ e $+4 \%$ ) correspondeu a $28,3 \%$ de manutenção partidária no Executivo. Desta forma, o impacto da política fiscal e da variação na arrecadação gerada por tributo patrimonial parece ter representado um efeito marginal sobre as chances de recondução partidária em governos municipais.

Administrações municipais abrem concursos, contratam servidores, fixam planos de carreiras e política salarial de seus funcionários. O número de servidores ocupados na administração direta e indireta dos municípios brasileiros passou de 4,8 milhões em 2005 para 6,6 milhões em 2015, significando que proporção equivalente a 3,2\% da população brasileira em 2015 estava ocupada nas administrações públicas municipais (IBGE 2015). Por outro lado, a escala do serviço público municipal está fortemente correlacionada com a dimensão da população local $\left(\mathrm{p}=.95^{* * *}\right)$ e a receita orçamentária $\left(\mathrm{p}=.92^{* * *}\right)$ (IBGE 2015).

Cerca de três quintos dos servidores públicos das administrações municipais brasileiras são estatutários, tendo ingressado por concurso público e possuindo estabilidade no cargo após três anos de permanência na função pública. Considerando sua distribuição em relação à escolaridade, observa-se uma tendência de redução na participação de estatutários com Ensino Fundamental, à medida que cresce o tamanho do município, caindo de $16,2 \%$, nos micro municípios, para 9,5\% nas grandes cidades. Estatutários com Ensino Médio não apresentam variações na sua participação conforme a escala do município. Aqueles com formação superior mantêm proporção estável em micros, pequenas e médias administrações, apresentando uma saliência $(29,2 \%)$ em cidades com mais de 100 mil habitantes.

Estudos sobre profissionalização de burocracias governamentais (Evans \& Rauch 1999; BID 2004; Dahlström, Lapuente \& Teorell 2012; Bersch, Praça \& Taylor 2017), utilizam duas categorias para observar sua presença na administração pública: autonomia, correspondendo a ingresso por concursos ou seleções públicas e garantia de carreiras profissionais de longo prazo; e capacidade, identificada por procedimentos meritocráticos de avaliação de desempenho e reconhecimento de competência técnica.

Nesta direção, como proxy visando isolar a dimensão de burocracia profissional nas administrações municipais, foi empregada a combinação "estatutário" com "formação superior". Embora não existam informações sobre a realização de avaliações periódicas de desempenho -que pudessem associar progressão na carreira a mérito profissional - a obrigatoriedade de ingresso por meio de concurso público somado à estabilidade no cargo indicam os requisitos de autonomia esperados à constituição de uma burocracia profissional. Em paralelo, pode-se associar a formação universitária aos atributos de conhecimento técnico necessários para o desempenho de sua atividade.

$\mathrm{O}$ procedimento seguinte consistiu em distinguir intervalos segundo a frequência de "estatutários com "formação superior" por municípios, cotejando esta informação com a participação relativa da receita gerada pela cobrança de IPTU na arrecadação municipal. Ou seja, pretendeu-se verificar, inicialmente, 
uma correspondência entre governos municipais com maior presença de "burocracias profissionais" e incremento na proporção de imposto imobiliário arrecadado. Os resultados são apresentados na Tabela 1, abaixo.

Em quase dois de cada três municípios nos quais servidores de carreira com formação superior representam menos de $5 \%$ do quadro de funcionários públicos, a arrecadação de IPTU representa menos de $10 \%$ da arrecadação do governo local. Em graus intermediários de profissionalização (até 15\%), uma participação relativa menor de IPTU mantém-se, embora com moderada tendência ascendente. Contudo, ao ultrapassar o umbral de $15 \%$ de "estatutários com formação superior”, o padrão inverte-se, com uma redução de 27,8 pontos percentuais na proporção de municípios nos quais o imposto patrimonial representa menos de $10 \%$ do arrecadado. Em contraste, em 40,3\% de administrações municipais nas quais a burocracia profissional apresenta proporção mais significativa, a receita gerada pelo IPTU ultrapassa a $20 \%$ da arrecadação local. Uma suposição preliminar poderia indicar que profissionalização do serviço público municipal pudesse ser afetada pelo tamanho do município. Entretanto, correlação $p$ entre proporção de "estatutários com formação superior" e população municipal apresenta coeficiente moderado $(0,12)$, sugerindo que embora a profissionalização burocrática possa ser favorecida pelo número de habitantes do município, esta contribui de forma limitada para a completa explicação daquele processo.

Escala populacional, custos políticos, relação negativa com transferências intergovernamentais, preferências redistributivas e profissionalização administrativa, são algumas das hipóteses encontradas nos estudos sobre política fiscal municipal para interpretar variações na arrecadação de IPTU.

Para cotejar a interação entre estas variáveis, modelou-se uma regressão logística, considerando como variável independente uma variável dummy 1 (IPTU > 20\%) e 0 (IPTU < 20\%). A variável burprof corresponde à ocorrência de estatutários com formação superior acima de $15 \%$ do quadro de servidores municipais, sendo esperada uma relação positiva com taxação direta, ou seja, pretende-se verificar que maior profissionalização contribui para maior arrecadação do imposto patrimonial. Left, quando o titular do Executivo municipal é filiado a partidos de esquerda (PT, PC do B, PDT, PSB); pop corresponde a 1 quando o município possui mais de 100 mil habitantes. A variável transf considerou os valores medianos das transferências federais voluntárias para cada município entre 2002 e 2012; desigualdade de renda em cada município foi considerada empregando o Índice Gini, que varia de 0 (maior dispersão) a 1 (maior concentração. A variável reel08 procura testar se a condição de reeleição partidária na eleição prévia (2008) ao período em questão incentiva a adoção desta política fiscal, com valor 1 quando o partido manteve o Executivo munici-

Tabela 1 - Relação entre percentual de estatutários com formação superior e variação na arrecadação IPTU (2012)

\begin{tabular}{lccc}
\hline & \multicolumn{2}{c}{ \% IPTU em relação arrecadação (2012) } \\
\cline { 2 - 4 } $\begin{array}{l}\text { Estatutários com } \\
\text { formação superior }\end{array}$ & Até 10\% & $\mathbf{1 0}$ a 20\% & Mais 20\% \\
\hline Até 5\% & & & \\
5 a 10\% & 62,4 & 14,5 & 23,1 \\
10 a 15\% & 56,3 & 20,1 & 23,6 \\
Mais 15\% & 47,4 & 23,1 & 29,5 \\
\hline
\end{tabular}

Fontes: Tesouro Nacional, IBGE (2015) e Atlas-UFRGS (2016). 
pal e 0 quando foi derrotado. Finalmente, dom08 considerou percentuais acima ou abaixo de 50\% de votos obtidos pelo candidato vencedor nas eleições para a prefeitura local em 2008. Embora a base de dados utilizada corresponda aos 5.570 municípios brasileiros, há lacunas de informação para alguns anos ou variáveis nas fontes de dados da IBGE (burprof, pop, gini), Tesouro Nacional (IPTU, transf, recmun) e TSE (left, dom08). Os resultados são encontrados abaixo (Tabela 2).

Variações na escala de arrecadação do IPTU conforme tamanho do município e perfil da burocracia governamental podem ser visualizados ainda por meio das informações contidas no Gráfico 5. Ele apresenta os valores médios da participação do IPTU na arrecadação municipal segundo o porte do município (micro/pequeno/médio/grande), bem como seu comportamento, à medida em que a administração municipal apresente proporções altas ou baixas de "estatutários com formação superior".

Administrações municipais com maior concentração de burocracia profissional apresentam razão de chance cerca de $80 \%$ maior de gerar maiores níveis de arrecadação de imposto imobiliário urbano do que aqueles que contam com

Tabela 2 - Regressão logística - Arrecadação IPTU em relação a variáveis escolhidas (2012)

\begin{tabular}{lccccc}
\hline & $\boldsymbol{B}$ & SE & Wald & Sig & Exp (B) \\
\hline burprof &, 58 & $(, 07)$ & 60,43 &, 000 & 1,79 \\
pop & 1,62 & $(, 15)$ & 118,12 &, 000 & 5,03 \\
gini & $-1,21$ & $(, 08)$ & 223,89 &, 000 &, 30 \\
transf &,- 10 & $(, 07)$ & 2,13 &, 144 &, 90 \\
left &, 01 & $(, 08)$ &, 01 &, 927 & 1,01 \\
dom08 &,- 40 & $(, 08)$ & 21,99 &, 000 &, 67 \\
reel08 &, 32 & $(, 07)$ & 19,39 &, 000 & 1,38 \\
Constant & -81 & $(, 06)$ & 179,84 &, 000 &, 44 \\
\hline
\end{tabular}

Fontes: Tesouro Nacional, IBGE (2015), TSE e Atlas-UFRGS (2016).

Gráfico 5 - Arrecadação IPTU em relação tamanho município e perfil burocracia (2012)

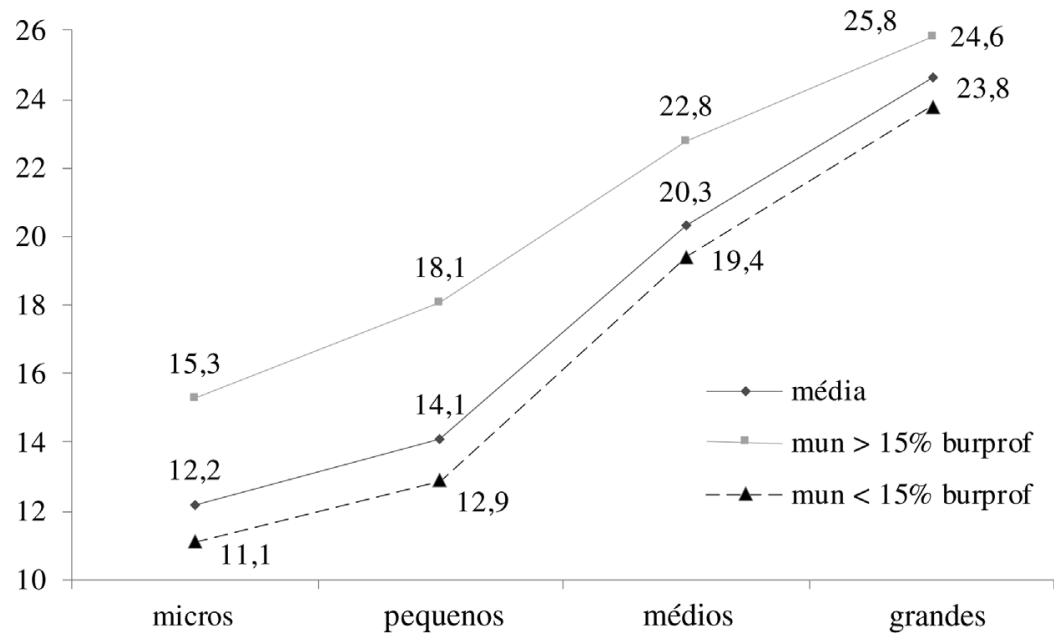

Fontes: Tesouro Nacional, IBGE (2015) e Atlas-UFRGS (2016). 
proporções inferiores de "estatutários com formação superior". Cidades com mais de 100 mil habitantes possuem cinco vezes mais chances de aprovar maior política fiscal com maior arrecadação de IPTU, em relação a prefeituras de municipalidades com menor população. Gini possui uma relação negativa com imposto patrimonial. Considerando que este índice varia de 0 (maior dispersão) a 1 (maior concentração), e que valores mais elevados indicam maior desigualdade, os resultados negativos indicam que cidades com menores índices de desigualdade de renda apresentam uma razão de chance de aproximadamente $70 \%$ de se situarem entre aquelas que mais arrecadam. Provavelmente uma distribuição mais equitativa do patrimônio imobiliário contribua para reduzir a desigualdade, minimizando, também, pressões por redistribuição da propriedade e renda via política fiscal. Dominância eleitoral apresenta relação negativa com incremento na receita patrimonial urbana, revelando que prefeitos eleitos com mais de $50 \%$ dos votos no primeiro turno possuem chances $33 \%$ menores de aumentar a participação relativa do IPTU na arrecadação municipal. Por outro lado, administrações municipais (2009/2012) antecedidas pela reeleição do partido à frente do governo nas eleições de 2008 apresentaram razão de chance $38 \%$ superiores de adotar maiores faixas de arrecadação do IPTU do que governos marcados por alternância partidária nas eleições prévias. Por fim, a odds ratio para esquerda e transferências intergovernamentais sugere pouco impacto na geração de chances para a definição de incremento na arrecadação de IPTU. Finalmente, o teste Wald para as variáveis incluídas no modelo indicou que transferências federais e partidos de esquerda não contribuíram significativamente para a explicação do modelo, contrariando expectativas da literatura sobre relação entre ideologia e política redistributiva ou maiores volumes de transferências federais voluntárias e desincentivo para arrecadação redistributiva.

Burocracias profissionalizadas fazem diferença significativa sobre a arrecadação de IPTU sobretudo em "micro" e "pequenos" municípios, apresentando variações de, respectivamente, $37,8 \%$ e $40 \%$ em relação às administrações com menor concentração de servidores com este perfil. Por outro lado, em municípios médios $(17,5 \%)$ e grandes $(8,4 \%)$, as discrepâncias são menos pronunciadas, sugerindo que o impacto promovido por este padrão de autonomia/capacidade parece ser mais residual

\section{Conclusão}

Este trabalho apresentou resultados de pesquisa sobre capacidades estatais em municípios brasileiros. Utilizando bancos de dados contendo informações demográficas, fiscais, sociais, políticas e administrativas dos mais de 5,5 mil governos municipais do Brasil, buscou-se identificar e compreender discrepâncias horizontais entre os municípios no que diz respeito a indicadores de sua capacidade estatal e o impacto destes recursos em seu potencial para tributar e implementar políticas urbanas. Adotou-se uma definição restrita de "capacidade estatal", relacionando-a à escala de profissionalização da burocracia governamental, entendida enquanto combinação de autonomia profissional e capacidade técnica. Para dimensionar sua presença nas administrações municipais, adotou-se a proporção de "estatutários com formação superior" no funcionalismo municipal.

A análise sobre efeitos da capacidade estatal restringiu-se à política tributária, especificamente as variações na arrecadação do imposto imobiliário urbano (IPTU). Conforme já registrado pela literatura, foi confirmado uma participação restrita deste tributo na receita dos municípios, com tendência declinante no intervalo analisado de 10 anos. Em paralelo, observou-se que a importância do IPTU nas finanças municipais cresce acompanhando o tamanho 
do município. Não há uma relação direta entre escala da tributação e preferências ideológicas presumíveis das legendas à frente do Executivo municipal, nem efeito significativo sobre as chances de continuidade partidária nas eleições seguintes.

População, incumbency e níveis de profissionalização do serviço público são as variáveis que mais afetam a escala da arrecadação do tributo, sendo que a burocracia profissional é um fator particularmente diferencial em "micro" e "pequenos" municípios. Taxação sobre patrimônio urbano configura uma arena redistributiva, nos termos fixados por Lowi, com a identificação e delimitação daqueles que deverão arcar com os custos da arrecadação, em um jogo perdeganha de soma-zero. Como salienta Lowi: "the nature of a redistributive issue is not determined by the outcome of a battle over how redistributive a policy is going to be. Expectations about what it can be, what it threatens to be, are determinative" (Lowi 2009, p.34).

Sob estas coordenadas, taxação patrimonial mobiliza potenciais perdedores, envolvendo custos políticos elevados. A maior arrecadação de IPTU em municípios grandes pode estar relacionada a dois fatores: (1) acesso à menor proporção do Fundo de Participação dos Municípios, projetando pressões por fonte alternativas de arrecadação própria; (2) maiores custos de coordenação social de proprietários urbanos, relacionado a seu número e diversificação em metrópoles. Enquanto em municípios menores um pequeno número de proprietários de patrimônio urbano pode mais facilmente coordenar ações e retaliação face à taxação de seus imóveis, a complexidade de grandes cidades torna sua ação mais onerosa social e politicamente. Em paralelo, prefeitos que acabaram de ser reeleitos (e não poderão mais sê-lo na próxima eleição), não precisam administrar os custos eleitorais de aumentar a arrecadação sobre patrimônio territorial.

Em que medida a profissionalização do serviço público municipal contribuiria para ampliar a arrecadação do imposto sobre patrimônio imobiliário? Uma explicação para esta relação pode residir em que indicadores de capacidade técnica que acompanham burocracias profissionalizadas pode incrementar seu potencial para equacionar "custos administrativos", como elaboração de cadastros, monitoramento de índices e revisão de valores venais. Em paralelo, o maior insulamento permitido pela autonomia de carreiras públicas contribuiria sob a forma de redução de custos de transação políticos associados à taxação sobre propriedade imobiliária em pequenas localidades. Burocratas de carreira não estão submetidos aos ciclos políticos e eleitorais, tendo desta forma maiores incentivos para equacionar os custos decorrentes de mobilização anti-taxação. Estudos de caso em escala micro sobre interações entre prefeitos, burocracias e legislativos municipais poderão trazer achados mais detalhados sobre circunstâncias e fatores que contribuem para incremento na arrecadação do IPTU.

Um ponto que não deve ser negligenciado consiste em que política fiscal redistributiva não equivale automaticamente a orçamento redistributivo. Steinmo (1989) já havia chamado a atenção para isto ao mostrar que a política fiscal norte-americana fora mais redistributiva (baseada em taxação sobre propriedade e renda) do que a sueca, orientada para tributos indiretos sobre o consumo. Paradoxalmente, registra-se elevados níveis de gasto social e vocação universal e redistributiva da política orçamentária no país escandinavo, conforme os conhecidos achados de Esping-Andersen (1990), entre outros. Discrepâncias entre incremento nos níveis de arrecadação do imposto patrimonial urbano e orçamentos sociais mais modestos em municípios brasileiros pode ser material revelador sobre a opacidade da política e das instituições governamentais locais. Mas isto será objeto de um próximo artigo. 
André Marenco (amarenco@terra.com.br) é Doutor em Ciência Política pela Universidade Federal do Rio Grande do Sul (URFGS) e Professor Titular do Departamento de Ciência Política e Programa de Pós-Graduação em Políticas Públicas da mesma universidade. Vínculo Institucional: Programa de Pós-Graduação em Políticas Públicas da Universidade Federal do Rio Grande do Sul, Porto Alegre, RS, Brasil.

Maria Tereza Blanco Strohschoen (mariaterezablancostrohschoen@gmail.com) é Bolsista IC/CNPq e aluna do curso de Políticas Públicas da Universidade Federal do Rio Grande do Sul (URFGS). Vínculo Institucional: Bacharelado em Políticas Públicas da Universidade Federal do Rio Grande do Sul, Porto Alegre, RS, Brasil.

William Joner (williamj147@gmail.com) é Bolsista IC/CNPq e aluno do curso de Políticas Públicas da Universidade Federal do Rio Grande do Sul. Vínculo Institucional: Bacharelado em Políticas Públicas da Universidade Federal do Rio Grande do Sul, Porto Alegre, RS, Brasil.

\section{Referências}

Abrucio, F. \& Sano, H., 2011. A experiência de cooperação interestadual no Brasil: formas de atuação e seus desafios. Cadernos Adenauer, 12(4), pp.91-110.

Abrucio, F.; Franzese, C. \& Sano, H., 2013. Trajetória recente da cooperação e coordenação no federalismo brasileiro: avanços e desafios. In J. Cardoso Jr. \& G. Bercovici, eds. República, Democracia e Desenvolvimento: contribuições ao Estado brasileiro contemporâneo. Brasília: IPEA.

Acemoglu, D. \& Robinson, J., 2012. Why Nations Fail? The Origins of Power, Prosperity and Poverty. New York: Crown.

Afonso, J.R. \&AMP; CASTRO, K., 2014. IPTU e finanças públicas municipais no Brasil: dificuldades e potencial . Texto de Discussão, 63. Fundação Getúlio Vargas.

Afonso, J.R.; Araújo, E.A. \& Nóbrega, M.A.R, 2012. The Urban Property Tax (IPTU) in Brazil: An Analysis of the Use of the Property Tax as a Revenue Source by Brazilian Municipalities. Working Paper. Lincoln Institute of Land Policy. 2013. IPTU no Brasil: um diagnóstico abrangente. FGV Projetos, 4, pp.9-80.

Alesina, A. \& Rosenthal, H., 1995. Partisan Politics, Divided Government and the Economy. New York: Cambridge University Press.

Almeida, M.H.T., 2005. Recentralizando a Federação? Revista de Sociologia e Política, 24, pp.29-40. DOI: 10.1590/s0104-44782005000100004

Almeida, M.H.T. \& Carneiro, L., 2003. Liderança Local, democracia e políticas públicas no Brasil. Opinião Pública, 9(1), pp.124-147. DOI: 10.1590/s0104-62762003000100005

Arretche, M., 2009. Continuidades e descontinuidades da federação brasileira: de como 1988 facilitou 1995. Dados, 52(2), pp.377-423. DOI: 10.1590/s0011-52582009000200004

2013. Quando instituições federativas fortalecem o governo central? Novos Estudos, 95, pp.39-57. DOI: 10.1590/s0101-33002013000100003

Avelar, L. \& Walter, M., 2008. Lentas mudanças: o voto e a política tradicional. Opinião Pública 14(1), pp.96-122. DOI: 10.1590/s0102-64452000000100011

Bahl, R., 2009. Property Tax Reform in Developing and Transition Countries. Washington: USAID.

Barone, L., 2010. Emprego público e política: uma radiografia da gestão 2005/2008 nos municípios brasileiros. In III Congresso Consad de Gestão Pública. Brasília.

Batista, M., 2013. Incentivos da dinâmica política sobre a corrupção: reeleição, competitividade e coalizões nos municípios brasileiros. Revista Brasileira de Ciências Sociais, 28(82), pp.87-106. DOI: 10.1590/s0102-69092013000200006 ,2015. Burocracia local e qualidade da implementação de políticas descentralizadas: uma análise da gestão de recursos federais pelos municípios brasileiros. Revista do Serviço Público, 66(3), pp.345-370.

Bersch, K.; Praça, S. \& Taylor, M., 2017. Bureaucratic Capacity and Political Autonomy within National States: Mapping the Archipelago of Excellence in Brazil. In M. Centeno; A. Kohli \& D. Yashar, eds. States in the Developing World. New York: Cambridge University Press.

Boix, C., 2003. Democracy and Redistribution. New York: Cambridge University Press.

Campello de Souza, M.C., 2006. Federalismo no Brasil: aspectos político-institucionais. Revista Brasileira de Ciências Sociais, 21(6), pp.7-40. DOI: 10.1590/s0102-69092006000200002

Castles, F. \& Obinger, H., 2007. Social Expenditure and the Politics of Redistribution. Journal of European Social Policy, 17(3), pp.206-222. DOI: 10.1177/0958928707078364

Centeno, M.; Kohli, A. \& Yashar, D., eds. States in the Developing World. New York: Cambridge University Press.

Cingolani, L., 2013. The State of State Capacity: A Review of Concepts, Evidence and Measures. Maastricht: UNU-MERIT.

Cingolani, L.; Thomsson, K. \& Crombrugghe, D., 2013. Minding Weber More than Ever? The Impact of State Capacity and Bureaucratic Autonomy on Development Goals. In ECPR General Conference. Bordeaux.

Codato, A.; Cervi, E. \& Perissinotto, R., 2013. Quem se elege prefeito no Brasil? Condicionantes do sucesso eleitoral em 2012. Cadernos Adenauer, 14(2), pp.61-84.

Cook, B. , 2010. Arenas of Power and New Policy Theory: Toward a Synthesis. In 2010 Annual Meeting of the American Political Science Association. Washington. 
Dahlström, C.; Lapuente, V.\& Teorell, J., 2012. Public Administration Around the World. In S. Holmberg \& B. Rothstein, eds. Good Government. The Relevance of Political Science. Cheltenham: Edward Elgar.

De Cesare, C., 2010. Panorama do imposto sobre a propriedade imobiliária na América Latina. Cambridge: Lincoln Institute of Land Policy.

,2007. Progressividade Fiscal no IPTU em Porto Alegre: discussão \& análise. Financiamento das cidades: instrumentos fiscais e de política urbana. In C. De Cesare \& E. Cunha, eds. Programa Nacional de Capacitação das Cidades. Brasília: Ministério das Cidades.

Dieguez, R.C., 2011. Autonomia, accountability e coesão interna: uma proposta de metodologia para análise política e institucional de consórcios intermunicipais. In II Fórum Brasileiro de Pós-Graduação em Ciência Política. São Carlos.

Dos Santos, L., 2009. Burocracia Profissional e a livre nomeação para cargos de confiança no Brasil e nos EUA. Revista do Serviço Público, 60(1), pp.5-28.

Esping-Andersen, G., 1990. The Three Worlds of Welfare Capitalism. New Jersey: Princeton University Press.

Evans, P., 1993. Embedded Autonomy: States and Industrial Transformation. Princeton: Princeton University Press. , 1995. O Estado como problema e solução. Lua Nova, 28-29, pp. 107-156. DOI: 10.1590/s0102-64451993000100006

Evans, P.; Huber, E. \& Stephens, J., 2017. The Political Foundations of State Effectiveness. In M. Centeno; A. Kohli \& D. Yashar, eds. States in the Developing World. New York: Cambridge University Press.

Evans, P., \& Rauch, J.E., 1999. Bureaucracy and Growth: A Cross-National Analysis of the Effects of Weberian State Structures on Economic Growth. American Sociological Review, 64(5), pp.748-765. DOI: 10.2307/2657374

Downs, A, 1957. An Economic Theory of Democracy. New York: Harper.

Evans, P. \& Rueschmeyer, D., 2002. The State and Economic Transformation: Toward an Analysis of the Conditions Underlying Effective Intervention. In P. Evans; D. Rueschmeyer \& T. Skocpol, eds. Bringing the State Back In. Cambridge: Cambridge University Press.

Falleti, T. 2005. A Sequential Theory of Decentralization: Latin American Cases in Comparative Perspective. American Political Science Review, 99(3), pp.327-346. DOI: 10.1017/s0003055405051695 2010. Decentralization and Subnational Politics in Latin America. Cambridge: Cambridge University Press.

Felisbino, R. ; Bernabel, R. \& Kerbauy, M., 2012. Somente um deve vencer: as bases de recrutamento dos candidatos à Prefeitura das capitais brasileiras em 2008. Revista de Sociologia e Política, 20(41), pp.219-234. DOI: 10.1590/s0104-44782012000100013

Fernandes, A. \& Araujo, S., 2015. A criação de municípios e a formalização de regiões metropolitanas: os desafios da coordenação federativa. Urbe, 7(3), pp.295-309. DOI: 10.1590/2175-3369.007.003.ao07

Fiani, R., 2014. Arranjos institucionais e desenvolvimento: o papel da coordenação em estruturas híbridas. In A. Gomide \& R. Pires, eds. Capacidades estatais e democracia: arranjos institucionais de políticas públicas. Brasília: IPEA.

Franzese, C., 2010. Federalismo cooperativo no Brasil: da Constituição de 1988 aos sistemas de políticas públicas. São Paulo: Fundação Getúlio Vargas.

Garson, S., 2007. Tributação imobiliária no Brasil: revendo desafios. In Seminário Internacional Tributação Imobiliária Iniciativas para o Fortalecimento da Ação Fiscal dos Municípios em Tributação Imobiliária. Salvador.

Geddes, B., 1986. Building State Autonomy in Brazil, 1930-1964. Los Angeles: University of California. 1990. Building State Autonomy in Brazil, 1930-1964. Comparative Politics, 22(2), pp.217-235. DOI: 10.2307/422315

Gomide, A. \& Boschi, R., 2016. Capacidades estatais em países emergentes: o Brasil em perspectiva. Rio de Janeiro: IPEA.

Gomide, A.; Silva, F. \& Pires, R., 2014. Capacidades estatais e políticas públicas: passado, presente e futuro da ação governamental para o desenvolvimento. In L. Monasterio; M. Neri \& S. Soares, eds. Brasil em desenvolvimento 2014: Estado, planejamento e políticas públicas. Brasília: IPEA.

Grín, E., 2012. Notas sobre a construção e a aplicação do conceito de capacidades estatais. Revista Teoria e Sociedade, 20, pp.121-143.

Guedes, J., 2001. Comentários à Lei de Responsabilidade Fiscal. Rio de Janeiro: IBAM.

Hibbs Jr., D., 1977. Political Parties and Macroeconomic Policy. American Political Science Review, 71(4), pp.1467-1487. DOI: $10.2307 / 1961490$

Huntington, S., 1968. Political Order in Changing Societies. New Haven: Yale University Press.

Kerbauy, M., 2005. As Câmaras Municipais brasileiras: perfil de carreira e percepção sobre o processo decisório local. Opinião Pública, 11(2), pp.337-365. DOI: 10.1590/s0104-62762005000200003

Klink, J., 2010. Governança das Metrópoles. São Paulo: Editora Annablume.

Kohli, A., 2010. State Capacity for Development. New York: UNDP.

Larcinese, V., 2007. Voting Over Redistribution and the Size of the Welfare State: The Role of Turnout. Political Studies, 55, pp.568-585. DOI: 10.1111/j.1467-9248.2007.00658.x

Lowi, T., 2009. Arenas of Power. Boulder: Paradigm Publishers.

Marenco, A., 2013. Topografia do Brasil profundo: votos, cargos e alinhamentos nos municípios brasileiros. Opinião Pública, 19(1), pp.1-20. DOI: 10.1590/s0104-62762013000100001

Mattos, E.; Rocha, F. \& Arvate, P., 2011. Flypaper Effect Revisited: Evidence for Tax Collection Efficiency in Brazilian Municipalities. Estudos Econômicos, 41(2), pp.239-267. DOI: 10.1590/s0101-41612011000200002

Melo, M., 2005. O sucesso inesperado das reformas de segunda geração: federalismo, reformas constitucionais e política social. Dados, 48(4), pp.845-889. DOI: 10.1590/s0011-52582005000400004 
Olsen, J., 2005. Maybe It Is Time to Rediscover Bureaucracy. Journal of Public Administration Research and Theory, 16(1), pp.1-24. DOI: 10.1093/jopart/mui027

Paes, N \& Bugarin, M., 2006. Parâmetros tributários da economia brasileira. Estudos Econômicos, 36(4), pp.699-720. DOI: 10.1590/s0101-41612006000400002

Pereira, A.; Nakabashi, L. \& Sachida, A., 2011. Qualidade das Instituições e PIB per Capita nos Municípios Brasileiros. Brasília: IPEA.

Piquet, L. \& Almeida, M.H.T., 2008. Definindo a arena política local: sistemas partidários municipais na Federação Brasileira. Dados, 51(2), pp.403-442. DOI: 10.1590/s0011-52582008000200006

Pires, R. \& Gomide, A., 2014. Capacidades estatais e democracia: arranjos institucionais de políticas públicas. Brasília: IPEA.

Rothstein, B., 2011. The Quality of Government: Corruption, Social Trust, and Inequality in International Perspective. Chicago: University Of Chicago Press.

Samuels, D., 2003. Ambition, Federalism, and Legislative Politics in Brazil. Cambridge: Cambridge University Press.

Samuels, D. \& Abrucio, F., 2000. The New Politics of the Governors: Subnational politics and the Brazilian Transition to Democracy. Publius, 30(2), pp.43-61.

Sátyro, N., 2013. Política estadual e desigualdade: por que alguns estados redistribuem mais do que outros? Dados, 56(3), pp.497-530. DOI: 10.1590/s0011-52582013000300002

Schmidt, M.G., 1996. When Parties Matter. A Review of the Possibilities and Limits of Partisan Influence on Public Policy. European Journal of Political Research, 30(2), pp.155-183. DOI: 10.1111/j.1475-6765.1996.tb00673.x

Sefter, T., 2006. Distributive and Redistributive Policy. In M. Moran; M. Rein \& R. Goodin, eds. Oxford Handbook of Public Policy. Oxford: Oxford University Press.

Selznick, P., 1984. TVA and the Grass Roots: A Study of Politics and Organization. Los Angeles/London: University of California Press.

Sepúlveda, C. \& Vazquez, J. M., 2009. Property Taxation in Latin-America: An Assessment and Options for Reform. In Conferência CEPALGTZ: Relaciones intergubernamentales y descentralización en América Latina. Santiago.

Smolka, M.O. \& Furtado, F., 1996. Argumentos para a reabilitação do IPTU e do ITBI como instrumentos de intervenção urbana (progressista). Revista Espaço \& Debates, 39, pp.87-103.

Soares, M., 2012. Repasses Financeiros e Voluntários da União aos Municípios Brasileiros: condicionantes políticos, sociais e técnicos. In $8^{\circ}$ Encontro da $A B C P$. Gramado.

Steinmo, S., 1989. Political Institutions and Tax Policy in the United States, Sweden and Britain. World Politics, 41(4), pp. 500-535. DOI: $10.2307 / 2010528$

Stepan, A., 1999. Para uma nova análise comparativa do federalismo e da democracia: federações que restringem ou ampliam o poder do demos. Dados, 42(2), pp.197-251. DOI: 10.1590/s0011-52581999000200001

Tilly, C., 2007. Democracy. Cambridge: Cambridge University Press.

Vieira, R., 2009. O tamanho do setor público no contexto do federalismo: um modelo aplicado aos municípios brasileiros. Brasília: IPEA.

Wittman, D., 1995. The Myth of Democratic Failure: Why Political Institutions are Efficient. Chicago: University of Chicago Press.

\section{Outras fontes}

ATLAS-UFRGS, 2016. Atlas da Política Municipal no Brasil. Universidade Federal do Rio Grande do Sul.

Brasil, 1988. Constituição da República Federativa do Brasil. Brasília: Centro de Documentação da Câmara dos Deputados. , 2000. Lei Complementar No 101 - Lei de Responsabilidade Fiscal. Brasília: Centro de Documentação da Câmara dos Deputados.

BID, 2007. A política das políticas públicas. Rio de Janeiro: Elsevier.

IBGE, 2015. Munic. Perfil de Informações Básicas Municipais.

RFB. Receita Federal do Brasil, 2014. Carga Tributária no Brasil 2014. Análise por tributos e base de incidência. Brasília: Receita Federal do Brasil.

Tesouro Nacional. Finanças do Brasil: Dados Contábeis dos Municípios. Disponível em: http://www.tesouro.fazenda.gov.br/pt_PT/contas-anuais. Acesso em: 27 nov. 2017.

TSE. Tribunal Superior Eleitoral. Estatísticas Eleitorais. Disponível em http://www.tse.jus.br/eleicoes/estatisticas/estatisticas-eleitorais. Acesso em: 27 nov. 2017. 


\title{
State Capacity, Bureaucracy and Taxation in Brazilian Municipalities
}

\begin{abstract}
Diagnostics on intergovernmental relations and implementation of public policies after the 1988 Constitution, emphasized are the decentralization, centralization or federative coordination. Without underestimating institutional mechanisms that structure vertical relationships between federal, state and municipal governments, this study aims to examine differences between the 5,500 Brazilian municipalities regarding indicators of its state capacity. The aim is to examine to what extent municipalities with professionalized bureaucracies were better able to take advantage of the transfer of responsibilities and political and administrative authority to local governments, expanding its potential for tax and implement public policies. It adopted a narrow definition of state capacity, using the "Weberian scale" proposed by Evans and as its measure. To operationalize it was considered the proportion of "statutory with higher education" among public servants in 5,500 Brazilian municipal administrations. As the dependent variable, we used the collection of property tax as a proportion of municipal own revenue. The results showed that municipal administrations with more professional public services increase their chance ratio for propriety tax collection.
\end{abstract}

Keywords municipal government; state capacity; bureaucracy; taxation; public policies.

This is an Open Access article distributed under the terms of the Creative Commons Attribution Non-Commercial License which permits unrestricted non-commercial use, distribution, and reproduction in any medium provided the original work is properly cited. 